\title{
Signo y memoria: \\ El fragmento como forma artística y comunicativa*
}

\author{
Jorge Esteban Zapata Garcés** \\ Recibido: 7 de febrero de 2017 \\ Enviado a pares evaluadores: 21 de febrero de 2017 \\ Aprobado por pares evaluadores: 30 de marzo de 2017 \\ Aprobado por comité editorial: 17 de abril de 2017 \\ D0l: 10.22395/csye.v6n11a7
}

\section{RESUMEN}

Este artículo demuestra cómo el collage (método artístico que combina imágenes y materiales de diferentes contextos), representa la idea de identidad usando signos como fragmentos derivados de la cultura y la geografía. Teorías sobre el signo y conceptos sobre memoria e identidad se interrelacionan en respuesta a situaciones críticas. El collage como una expresión artística del siglo XX muestra cómo identidad y memoria son concebidas a través del uso de signos culturales.

Palabras clave: Identidad, memoria, signo, fragmento, cultura, territorio, global, local, geografía, collage, pintura.

Este artículo es resultado de investigación del trabajo titulado Translocation and Memory: Cultural Experiences as Artistic Influence presentado para obtener el título de M. F. A. (Master of Fine Arts) de la University of Calgary (Canadá) en 2015.

** M. A. University of Northern Iowa. M. F. A. University of Calgary. Profesor de cátedra de la Universidad EAFIT. Correo electrónico: artemoderno77@gmail.com 


\section{Sign and memory: The fragment as an artistic and communicative form}

\section{ABSTRACT}

This article reaffirms how collage (artis- tions. Collage as an artistic expression of tic method, whereby materials and images the twentieth century shows how identity are combined from different contexts), and memory are conceived through the use establishes a communication via signs that of cultural signs.

derive from associations with geography and culture. Drawing on multiple theories of signs, cultural memory and identity are interrelated in response to critical situa-

Keywords: Identity, memory, sign, fragment, culture, location, global, local, geography, collage, painting. 


\section{Introducción}

Parámetros culturales como lengua, raza, costumbres y ambiente son determinantes en procesos creativos. En la producción de obras, los signos y su interpretación definen la noción de identidad cultural. Para fines de este artículo el collage se define como una técnica pictórica artística y bidimensional que incorpora elementos de muy variadas fuentes tales como telas, texturas o productos gráficos, que sean propios de una cultura o de una cultura ajena para producir un efecto de contraste. Dicho contraste se manifiesta en signos como huellas, símbolos e íconos. Posteriormente se hará claridad de la definición de estos conceptos.

Se hará también una síntesis histórica del collage donde se muestra su desarrollo como técnica artística fundamentada en los conceptos de signo, lenguaje y fragmento. Se utilizarán las definiciones de memoria expuestas por Umberto Eco en la novela La misteriosa llama de la reina Loana para entender el concepto de collage relacionado con identidad. Igualmente se hará mención de artistas como Pablo Picasso, George Braque, Kurt Schwitters y Mimo Rotella exponentes del collage en el siglo XX.

Finalmente se explicará la relación del collage con el arte urbano y se enunciará la obra Jitish Kallat quien es una figura relevante del arte contemporáneo.

\section{Definicion e historia del collage}

Tenía fragmentos de pensamientos, estaba claro que me estaba despertando, pero no podía moverme. Si solo pudiera mantenerme despierto. ¿Me he vuelto a dormir? ¿Horas, días, siglos? UMBERTO ECO (2005)

La técnica del collage surge oficialmente con Pablo Picasso y George Braque. Utilizando fragmentos de revistas Pablo Picasso fue el primer artista que combinó material gráfico y óleo en 1912 en la obra titulada Guitarra. Contemporáneo de Picasso y de Braque y como uno de los representatantes del dadaismo, Kurt Schwitters concibió el metodo Merz basado en la libre asociación de connotación freudianda con apariencia ilógica. Combinando material gráfico derivado de objetos encontrados de imágenes como afiches y material promocional, Schwitters se apropia de estos elementos como sustrato creativo en una nueva manera de ver la pintura que busca interpretar la realidad del mundo (Schmalenbach, 1982). La idea de fragmento como elemento expresivo y de lenguaje contribuyó al desarrollo del arte en la primera mitad del siglo XX. El collage ha influenciado el concepto de pintura y su organización compositiva y temática. 
Concebido por los dadaístas y los surrealistas para crear imágenes, el collage ha representado un medio de comunicación y expresión (Ades, Cox y Hopkins 1999). Los signos se entrelazan en una totalidad visual referida al concepto de identidad donde revistas, imágenes de publicidad, fotografías y afiches son usados para representar fragmentos de civilización, territorio y sociedad. Estos residuos actúan como signos en respuesta a las experiencias sociales del artista. Incorporando estas "partes del mundo" se crean conexiones con el tiempo y la realidad. El collage introduce relaciones visuales entre lugares geográficos que permiten nuevos significados. Para la comprensión de lo que es el collage se utilizan los conceptos de Charles Sanders Pierce (1839-1914) quien definió la relación entre signo y lenguaje.

Definido como un objeto, un fenómeno o una accion material, los signos sustituyen objetos y fenómenos del mundo real. Los signos se convierten en una expresión que nos permite tener un sentido de realidad a través de diferentes jerarquías de ordenamiento visual. Colores, texturas, superficies, formas y textos son signos y estructuras fundamentales del collage. Charles Sanders Pierce establece una distinción del concepto de signo a partir de tres categorías básicas: iconos, índices y símbolos (Burks, 1949). Una forma de examinar los componentes del collage y su relativa función como signos es aplicando dichas categorías.

Los iconos se definen como representaciones en fotos y pinturas que sustituyen personajes y objetos reales manteniendo una similitud con lo existente. Las formas representadas en iconos nos llevan a entender la realidad. Para mejor comprensión la imagen de Marilyn es un icono que describe la belleza de una mujer. En este caso se amplía la extensión del concepto de icono como imagen religiosa utilizada en el cristianismo ortodoxo.

Los símbolos sugieren ideas como réplicas del mundo, distantes de nuestra percepcion e inmediato entendimiento. Tal es el caso de las representaciones simbólicas como escudos, banderas nacionales y el símbolo de la justicia y la paz. Los índices son marcas que nos llevan a conclusiones e interpretaciones. Las señales de humo, las pisadas en la arena y los trazos o gestos pictóricos son ejemplos de índices o indicios. Gracias a su claridad expresiva iconos e índices ofrecen un punto inmediato de entrada entre la realidad y la imagen. Iconos e índices son componentes fundamentales del collage que, como representación artística, es también un lenguaje y se define como un medio de comunicación. Ofreciendo una conexión entre emisor y receptor, los signos allí representados equivalen a mensajes que relacionan experiencias con diferentes contextos.

En la segunda mitad del siglo XX surge el decollage. No solo el collage sino también el decollage han generado nuevos significados asociados con nociones de arte y fragmento. Mimmo Rotella fue un artista italiano conocido por su técnica de decollage en la segunda mitad del siglo XX. Rotella rasgaba tiras de 
pósters y las pegaba al lienzo asemejando los carteles de los muros de la ciudad moderna. El arte de Rotella esta relacionado con la psycogeografía definida como los efectos específicos del ambiente geográfico en las emociones y el comportamiento (Debord, 1995). Rotella se apropia de material gráfico promocional que hace parte del paisaje urbano para hacer referencias de una realidad colectiva y personal. Con el decollage se define nuevamente el concepto de representación artística tras una larga crisis social y cultural en Europa.

En el collage, imágenes y objetos manifiestan su propia presencia y su proximidad creando nuevas metáforas y nuevos lenguajes. El lenguaje es entendido como un sistema de signos que facilitan la comunicación. Los idiomas y las palabras, por ejemplo, estan constituidos por sintaxis basadas en reglas y principios para formar mensajes. Conceptos como lenguaje y fragmento le dan la posibilidad al collage de una mejor comprensión.

Derivada del latin frangere que significa romper, la idea del fragmento desde un punto de vista linguístico establece un punto de comunicación a través de un giro cíclico entre la parte y el todo. Una sinécdoque o metonimia, por ejemplo, es una figura linguística que nos ayuda entender sustituciones entre el fragmento y el mundo físico.

El fragmento está relacionado con el collage en la importancia de las imágenes para una persona y es usada metafóricamente. En la novela La misteriosa llama de la reina Loana, de Umberto Eco, por ejemplo, libros, carteles, fotografias y discos de acetato son nociones de signos que hacen parte de la cultura popular y de la memoria colectiva. Giambattista Bodoni, personaje principal, tras recuperarse de un derrame cerebral, enlaza mentalmente imágenes de la cultura popular para descubrir quién es. En la novela Bodoni actúa como un detective de su propia identidad (Prada Londoño, 2006). Tres tipos de memoria son descritos: memoria implícita que implica un mecanismo mental de supervivencia, memoria episódica que corresponde a nuestros recuerdos y a nuestra identidad, y memoria semántica o colectiva que es la que nos permite formar categorías generales como carro, mujer, edificio, etc (Eco, 2005, p.12). Identidad, memoria y fragmento son conceptos que logran establecer una conexión de semejanza y equivalencia. Consecuentemente, el observador de un collage actúa como un investigador analizando los signos en la producción de significados.

\section{La obpa de Jitish kallat y los contextos urbanos}

En la actualidad, el arte urbano se ha convertido en extensión del collage como práctica artística mediante el uso de stencils, stickers, marcas e imágenes impresas en papel periódico que se adhieren a los muros de la ciudad (Keys, 2008). De igual manera, el arte urbano se inserta en expresiones artísticas más tradicionales como en la pintura sobre lienzo cuyos signos referencian también 
ambientes urbanos. El graffiti o arte callejero es una forma de expresión global que artistas usan para comunicarse interviniendo el espacio público.

Considerando cómo las circunstancias culturales inciden en la disposición de un individuo, la inclusión de signos en el arte forma nuevas narrativas. Fragmentos visuales se convierten en componentes de memoria donde el signo como elemento de representación en el collage adopta un carácter de juego y de un nuevo significado. Las referencias históricas y contemporáneas del collage han contribuido al establecimiento de nociones de identidad cultural y artística.

La identidad cultural es un componente desestabilizador en la cual la memoria establece una relación con el contexto. El concepto de identidad mezcla aspectos como raza, cultura y lenguaje, y sus respectivas interacciones establecen procesos de comunicación entre personas de diferentes origenes (Jackson II, 2010). También arquitectura y ambiente como variables culturales comprometen la experiencia estética y emocional de un individuo. La ausencia de referentes culturales en otros territorios permite entonces a un artista el ensamble de elementos locales y globales.

La práctica del collage se contextualiza en el escenario artístico actual como manifestación artística que referencia ámbitos culturales. La noción de signos culturales formulados como fragmentos se asocia con el concepto de memoria colectiva definida por Umberto Eco. Collages como Baggage Claim (p.e. fig. 1), que analizaremos a continuación, convierte el espacio bidimensional en un escenario de conflicto e interrogación. Mencionaremos aspectos de esta pintura como ejemplo de aproximación lingüística y comunicativa.

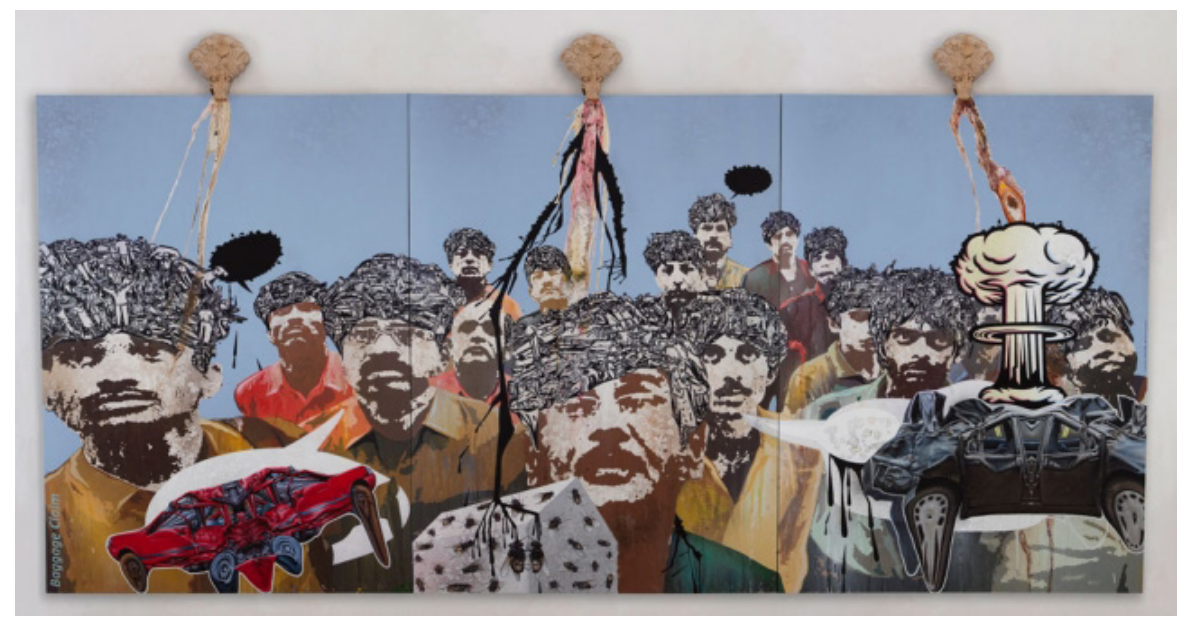

Figura 1. Baggage Claim, 2010, recuperado de http://www.arndtfineart.com/website/artist_ 1066 
La pintura del artista Jitish Kallat traducida al español como Reclamación de bagaje (término utilizado para expresar los antecedentes de un grupo de personas) expresa situaciones de desplazamiento, alienación e incomodidad de asentamientos urbanos. Apuntando directamente la idea de identidad, los rostros de Kallat son representados como espectadores de un trágico espectáculo. Su atención se centra fuera del cuadro y parecieran asistir a una procesión. Con inscripciones de aglutinación urbana en sus cabezas como marcas de su propia realidad, Kallat representa el desánimo y abatimiento de personas del común. Sus voces están constreñidas irónicamente en globos o bocadillos (convención para historietas y caricaturas) que sustituyen objetos por palabras. La unión de elementos realistas y elementos de cómic no solo se contrastan visualmente sino que también referencian ámbitos culturales.

Una de las figuras más importantes del arte contemporáneo es Jitish Kallat. De nacionalidad India Kallat es un representante importante de la cultura y el arte de su país. Conectado con las circunstancias sociales de la India, ideas como identidad nacional e intercomunicación global se asocian con el discurso de los más desposeídos en la obra de Kallat (Cuno, 2011).

Sintetizando algunos elementos de lo analizado en la obra, signos de identidad se hacen presentes través del collage. Usando iconos y símbolos identificables de una cultura, la memoria como parte de la identidad es redefinida y adapta su significado en relaciones de contexto. En el collage aspectos relacionales en una superficie se conectan dando pie a conversaciones en red. Referencias particulares se presentan como pistas de un acertijo visual que referencia nociones de historia y memoria.

\section{Conclusiones}

Grafitis, carteles comerciales, manifestaciones sociales y políticas, monumentos, lenguajes que representan a las principales fuerzas que actúan en la ciudad.

\section{NÉStOR GaRCía CANCLINI (1989)}

El collage como método artístico, que combina imágenes y materiales de diferentes contextos, representa el concepto de identidad usando signos como fragmentos derivados de la cultura y la geografía. Uniendo lo local y lo global en directas referencias a la idea de fragmento, los signos culturales se sitúan en el collage definiendo condiciones sociales y culturales. Por medio del collage usando elementos de un contexto urbano específico se transponen experiencias culturales de diferentes territorios. 
Disputas o colisiones que se generan tras la interacción de dos o más culturas prueban nociones de memoria e identidad en un mundo global. Manipulando signos culturales se puede visualizar y construir una obra de arte como testimonio de memoria. Los signos son parte de la idea de identidad cultural que reafirma la función comunicativa del collage en el contraste de sus elementos compositivos.

\section{Referencias bibliográficas}

Ades, D. (1999). Marcel Duchamp. London: Thames and Hudson. Ltd.

Burks W, A. (1949). Icon Index and Symbol, Philosophy and Phenomenological Research, 9, 4, 673-689.

Cuno, J. (2011). Conversation with Jitish Kallat. Art Institute of Chicago Museum Studies 36, 2, 67.

Debord, G. E. (1995). Introduction to a Critique of Urban Geography. Paris, Francia: Nothingness.org, The library, Les Levres Nues. Recuperado de http://library.nothingness.org/articles/SI/en/display/2>

Eco, U. (2005). The Mysterious Flame of Queen Loana. Nueva York, Estados Unidos, Harcourt Inc.

García Canclini, N. (1989). Culturas híbridas: Estrategias para entrar y salir de la modernidad. México, Grijalbo.

Jackson II, L. (2010). Culture, ethnicity and race. Encyclopedia of Identity.1st ed, Thousand Oaks, Estados Unidos. Sage publishing Inc.

Keys, K. (2008). Contemporary Visual Culture Jamming: Redefining Collage as Collective, Communal and Urban. Art Education 61, 2, 98-101.

Prada Londoño, M. (2006). Lectura, memoria e identidad en un texto de ficción: La

misteriosa llama de la reina Loana, Granada, España. Realidad y ficción, Revista Lindaraja. Recuperado de http://www.filosofiayliteratura.org/lindaraja/ricoeur/lecturamemoriaidentidad.htm

Schmalenbach, W. (1982). La vida de Kurt Schwitters. Madrid, España: Fundación Juan March. Recuperado de http://www.merzmail.net/vidaks.htm

\section{Figuras}

Kallat, J. (2010). Baggage Claim. (Figura 1). Recuperado de ARNDT http://www.arndtfineart.com/ website/artist_1066 